\title{
Aerosolized L-epinephrine vs Budesonide for Post-extubation Stridor: A Randomized Controlled Trial
}

\author{
A SinHa, M JaYASHREE AND S SinghI \\ From the Department of Pediatrics, Postgraduate Institute of Medical Education and Research, Chandigarh, India. \\ Correspondence to: Dr Jayashree Muralidharan, Additional Professor of Pediatrics, Advanced Pediatrics Centre, PGIMER, \\ Chandigarh 160 012, India.mjshree@hotmail.com \\ Received: August 8, 2008; Initial review: August 29, 2008; Accepted: April 24, 2009.
}

Objective: To compare the efficacy and adverse effects of aerosolized L-epinephrine vs budesonide in the treatment of post-extubation stridor.

Study design: Randomized controlled trial.

Setting: Pediatric intensive care unit (PICU) of a tertiary teaching and referral hospital.

Subjects: Sixty two patients with a stridor score $\geq 4$ following extubation.

Intervention: Patients were randomized to receive either aerosolized L-epinephrine $(n=32)$ or budesonide $(n=30)$. Respiratory rate, heart rate, stridor score, blood pressure and oxygen saturation were recorded from 0 min to 24 hours.

Outcome measures: Stridor score remaining at $\geq 4$, need for re-nebulization and re-intubation between $20 \mathrm{~min}-24$ hours were primary outcome measures. Tachycardia (HR $>$ normal for age), hypertension (BP >95th centile for age) and hypoxia (SpO2 <92\% for $5 \mathrm{~min}$ ) were secondary outcome measures.
Results: Both drugs showed a significant and comparable decline in the median $(95 \% \mathrm{Cl})$ stridor scores from baseline to $60 \mathrm{~min}$ [4 (4.10-4.50) to $2.00(1.46-2.67)$ for budesonide vs $4(4.12-5.00)$ to 2.00 (1.31 -2.75) for epinephrine]. At 2 hours, the stridor scores were significantly lower in the epinephrine as compared to budesonide group [0.00 (0.69-1.81) vs 3.00(1.75-3.32); $P$ $=0.02)]$. However, the proportion of patients with stridor score $\geq 4$ at any time between 20 min- 24 hrs $(53.3 \%$ vs 53.1\%; $P=0.99$ ), need for renebulization ( $40 \%$ vs $43.8 \%$; $P=0.76)$ and re-intubation ( $20 \%$ vs $25 \%, P=0.638)$, and adverse effects were similar in both groups.

Conclusions: Both aerosolized L-epinephrine and budesonide were equally effective in their initial therapeutic response in post-extubation stridor. However, epinephrine showed a more sustained effect.

Key words:Budesonide, Epinephrine, Extubation, Stridor.

Published online: 2009 September 3. PII:S097475590800491-1

$\mathrm{T}$ he most serious and immediate complication of extubation in young children is laryngeal edema; the incidence of post extubation stridor in the Pediatric intensive care unit (PICU) is described to be between 2-25\%(1-5). Aerosolized epinephrine has been found to be an effective therapy in both infective and postextubation stridor(6,7). The action of epinephrine, however, is transient and there is a potential risk of rebound laryngeal edema, which may limit the repeated use of this drug(7). Treatment with steroids provides a sustained effect due to their anti-inflammatory action. Intravenous dexamethasone was found to be effective in pre-extubation and post- extubation states thus decreasing the risk of post-extubation stridor by around 40\%(8). Theoretically, inhaled steroids with a similar mechanism of action as systemic steroids should be more advantageous due to direct delivery at the site of action, lesser dose needed and fewer side effects. Thus, aerosolized budesonide when used in the

Accompanying Editorial: Pages 307-308.

treatment of croup was found to reduce edema without any side effects $(9,10)$. Trials comparing aerosolized epinephrine and budesonide in the treatment of infective croup have shown similar 
efficacy and safety of both the drugs(11). However, there are no studies comparing these two drugs in the treatment of post-extubation stridor.

\section{MethodS}

The trial was conducted in the PICU of a multispeciality urban teaching and referral hospital with 1200 beds over a period of 11 months from February 2004 to January 2005, after approval from the Institute's Ethics Committee.

Patients demonstrating hoarseness of voice, barking cough and/or inspiratory stridor with a stridor score $\geq 4$ (Table I) after extubation, were enrolled after obtaining a written informed consent from parents or guardians. The demographic details, admission diagnosis, indication for PICU admission, Pediatric risk of mortality (PRISM) III scores, duration of mechanical ventilation and indication, type and duration of intubation were recorded at the time of inclusion.

Following extubation, all patients were administered humidified oxygen by nasal prongs or facemask with an oxygen flow of $6 \mathrm{~L} / \mathrm{min}$. Patients who fulfilled the inclusion criteria were randomized to receive either aerosolized L-epinephrine [(Group I (E)] or budesonide [Group II (B)]. Randomization by stratification (varying block randomization) was done so as to distribute patients with primary upper airway disease into both groups evenly. A primary upper airway disease was defined as primary pharyngeal, laryngeal or tracheal infections, trauma to upper airway or anatomical malformations of upper airway. A person who was not directly involved in the study did the random number allocation.

After randomization, Group I(E) received Lepinephrine $1 \%$ solution $0.25 \mathrm{~mL}$ in $2 \mathrm{~mL}$ normal saline, nebulized over 15-20 min with face mask and $6 \mathrm{~L} / \mathrm{min}$ of oxygen flow. Group II (B) received budesonide $1000 \mu \mathrm{g}(2 \mathrm{~mL})$ nebulized over 15-20 min with face mask and $6 \mathrm{~L} / \mathrm{min}$ of $\mathrm{O}_{2}$ flow. Respiratory rate (RR), stridor score, heart rate (HR), blood pressure (BP) and oxygen saturation $\left(\mathrm{SpO}_{2}\right)$ were recorded for each patient immediately before aerosol administration (time 0) and at 20, 40 and 60 mins; and at 2, 4, 8, 12 and 24 hours. Stridor score
TABLE I STRIDOR SCORING SYSTEM

\begin{tabular}{|c|c|}
\hline Clinical findings & Points \\
\hline \multicolumn{2}{|l|}{ Level of consciousness } \\
\hline Normal (including sleep) & 0 \\
\hline Altered mental status (lethargy) & 5 \\
\hline \multicolumn{2}{|l|}{ Cyanosis in room air } \\
\hline None & 0 \\
\hline When agitated & 4 \\
\hline Cyanosis at rest & 5 \\
\hline \multicolumn{2}{|l|}{ Inspiratory stridor } \\
\hline None & 0 \\
\hline When agitated & 1 \\
\hline At rest & 2 \\
\hline \multicolumn{2}{|l|}{ Air movement } \\
\hline Normal & 0 \\
\hline Decreased & 1 \\
\hline Markedly decreased & 2 \\
\hline \multicolumn{2}{|l|}{ Retractions } \\
\hline None & 0 \\
\hline Mild (alar flaring) & 1 \\
\hline Moderate (suprasternal and intercostal) & 2 \\
\hline Severe (all accessory muscles used) & 3 \\
\hline Maximum total points & 17 \\
\hline
\end{tabular}

Adapted from Nutman, et al.(6).

remaining at $\geq 4$, need for re-nebulisation, and/or reintubation at any time between 20 min-24 h were identified as primary outcome variables.

Children in whom the stridor score remained $\geq 4$ or worsened after receiving therapy, were renebulized with L-epinephrine (conventional protocol). The need for reintubation was decided by the treating physician based on combination of variables i.e. $\mathrm{HR}, \mathrm{RR}$, stridor score and $\mathrm{SpO}_{2}$.

Sample size: Assuming a failure rate of $40 \%$ in Lepinephrine group and a desired reduction of failure rate to $10 \%$ in the budesonide group, with an $\alpha$ error of $5 \%$ and power of $80 \%$, we calculated that approximately 30 subjects would be required in each group.

Statistical analysis: Data are presented as mean \pm SD, median and percentages wherever applicable. 
Parametric data were analyzed using the Student's ' $t$ ' test and non-parametric data with Mann- Whitney U test. Categorical data were analyzed with Chi-sqaure or Fisher's exact test. Continuous variables measured at different time intervals between the groups were compared using the repeated measures ANOVA. The linear trend in proportion between the groups was analyzed with Chi-square. The statistical packages used in the study were SPSS (version 10.0) and Epi Info 2000 (version 6.0).

\section{RESUlts}

Of the 370 patients admitted to the PICU during the study period, 196 (52.9\%) were intubated for various reasons. Sixty-two (31.6\%) of the intubated patients fulfilled the inclusion criteria and were randomized (Fig.1). Their baseline characteristics are summarized in Table II.

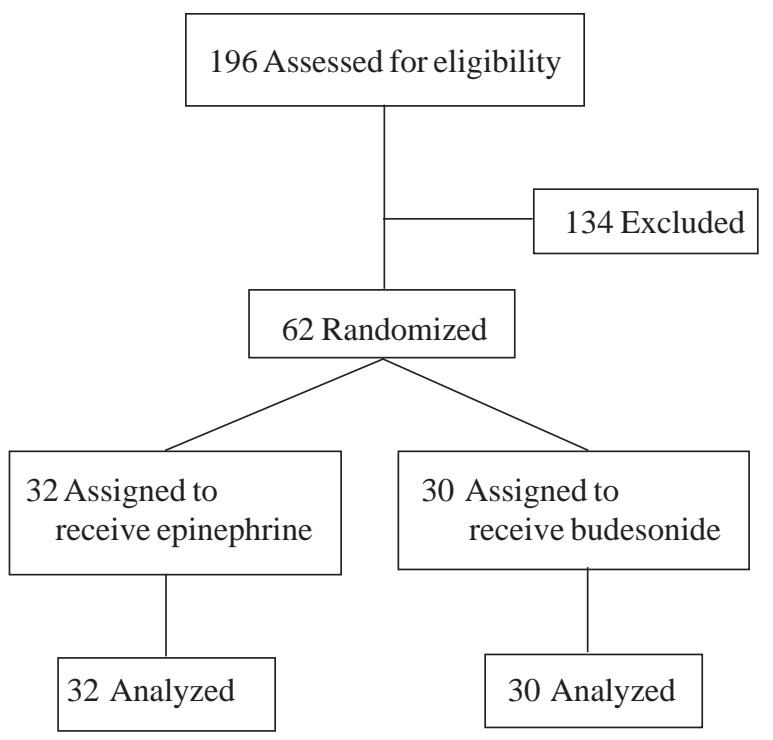

FIG. 1 Study flow chart.

TABLE II Baseline Characteristics OF THE StUdy SubJects

\begin{tabular}{llll}
\hline & Group I (E) $n=32$ & Group II (B) $n=30$ & $P$ value \\
\hline Age (mo), mean \pm SD & $34.7 \pm 38.4$ & $38.6 \pm 41.9$ & $0.80^{*}$ \\
Males & 26 & 24 & $0.58^{* * *}$ \\
PRISM score, median (Centile range) & $17(5-36)$ & $15(3-33)$ & $0.72^{* *}$ \\
Indication for intubation $n(\%)$ & & & \\
$\quad$ Respiratory failure & $11(34.4)$ & $11(36.7)$ & $0.57^{* * *}$ \\
$\quad$ Shock & $6(18.8)$ & $2(6.7)$ & \\
$\quad$ Respiratory failure + shock & $3(9.4)$ & $3(10)$ & \\
$\quad$ Low Glasgow Coma score & $4(12.5)$ & $3(10)$ & $0.55^{* *}$ \\
$\quad$ Raised Intracranial pressure & $4(12.5)$ & $9(30)$ & $0.79^{* *}$ \\
$\quad$ Upper airway obstruction & $4(12.5)$ & $2(6.7)$ & $0.59^{* *}$ \\
Duration(d), median (range) & & & $0.19^{*}$ \\
$\quad$ Intubation & $10(3-33)$ & $8.5(2-50)$ & $0.01^{*}$ \\
$\quad$ Mechanical Ventilation & $9(1-32)$ & $7.5(2-39)$ & $0.47^{*}$ \\
Stridor score, median & $4(4-5.5)$ & $4(4-5)$ & $0.17^{*}$ \\
Respiratory rate, mean \pm SD & $35.9 \pm 6.6$ & $38.3 \pm 8$ & $0.25^{*}$ \\
Heart rate, mean \pm SD & $119.8 \pm 20.4$ & $132.8 \pm 19.3$ \\
Systolic blood pressure, mean \pm SD & $98 \pm 10.2$ & $100.5 \pm 16.2$ & $64.5 \pm 15.7$ \\
Diastolic blood pressure, mean \pm SD & $59.6 \pm 12.2$ & $98.7 \pm 2$ & \\
$\mathrm{O}_{2}$ saturation, mean \pm S.D & $95.9 \pm 15.8$ & & \\
\hline
\end{tabular}

*Student's 't'test, **Mann Whitney U test, ***Chi Square test. 
TABLE III STRIDOR SCORE $\geq 4$ AT DifFERENT TIME INTERVALS

\begin{tabular}{|c|c|c|c|}
\hline Time Interval & $\begin{array}{r}\text { Group } \\
\text { II(B) } \\
\end{array}$ & $\begin{array}{r}\text { Group } \\
\mathrm{I}(\mathrm{E}) \\
\end{array}$ & $\begin{array}{r}P \\
\text { value } \\
\end{array}$ \\
\hline \multicolumn{4}{|l|}{ Baseline } \\
\hline Stridor score $\geq 4 ; n(\%)$ & - & - & - \\
\hline Median score $\left(5-95^{\text {th }}\right.$ cent & ile) $4(4-5)$ & $4(4-8)$ & 0.59 \\
\hline \multicolumn{4}{|l|}{20 min } \\
\hline Stridor score $\geq 4 ; n(\%)$ & $11(36.7 \%)$ & $9(28.1 \%)$ & 0.47 \\
\hline Median (5-95 ${ }^{\text {th }}$ centile) & $2.5(1-5)$ & $2.5(0-5)$ & 0.79 \\
\hline \multicolumn{4}{|l|}{$40 \min$} \\
\hline Stridor Score $\geq 4 ; n(\%)$ & $8(26.7 \%)$ & $8(25.0 \%)$ & 0.88 \\
\hline Median (5-95 th centile) & $2(0-4)$ & $2(0-5)$ & 0.91 \\
\hline \multicolumn{4}{|l|}{$60 \min$} \\
\hline Stridor score $\geq 4 ; n(\%)$ & $6(20 \%)$ & $6(18.8 \%)$ & 0.90 \\
\hline Median (5-95 ${ }^{\text {th }}$ centile) & $2(0-5)$ & $2(0-6)$ & 0.68 \\
\hline \multicolumn{4}{|l|}{2 hours } \\
\hline Stridor score $\geq 4 ; n(\%)$ & $10(33.3 \%)$ & $5(15.6 \%)$ & 0.10 \\
\hline Median (5-95 ${ }^{\text {th }}$ centile) & $3(0-5)$ & $0(0-4)$ & $0.01^{*}$ \\
\hline \multicolumn{4}{|l|}{4 hours } \\
\hline Stridor score $\geq 4 ; n(\%)$ & $5(16.7 \%)$ & $5(15.6 \%)$ & 0.91 \\
\hline Median (5-95 ${ }^{\text {th }}$ centile) & $1.00(0-4)$ & $0.00(0-4)$ & 0.45 \\
\hline \multicolumn{4}{|l|}{8 hours } \\
\hline Stridor score $\geq 4 ; n(\%)$ & $4(13.3 \%)$ & $4(12.5 \%)$ & 0.92 \\
\hline Median (5-95 ${ }^{\text {th }}$ centile) & $1(0-4)$ & $0(0-4)$ & 0.09 \\
\hline \multicolumn{4}{|l|}{12 hours } \\
\hline Stridor score $\geq 4 ; n(\%)$ & $2(6.7 \%)$ & $4(12.5 \%)$ & 0.44 \\
\hline Median (5-95 ${ }^{\text {th }}$ centile) & $0(0-4)$ & $0(0-4)$ & 0.67 \\
\hline \multicolumn{4}{|l|}{24 hours } \\
\hline Stridor score $\geq 4 ; n(\%)$ & 0 & $1(3.1 \%)$ & 0.33 \\
\hline Median (5-95 th centile) & $0(0-3)$ & $0(0-3)$ & 0.35 \\
\hline
\end{tabular}

*P value $<0.05$ by Mann Whitney U test.

The median (95\% CI) stridor scores from baseline (0min) to 24 hours and corresponding proportion of subjects with stridor score $\geq 4$ at different time intervals is depicted in Table III. The proportion of patients with stridor score $\geq 4$ at any time between $20 \mathrm{~min}-24 \mathrm{hrs}$ between budesonide and epinephrine group was $53.3 \%$ and $53.1 \%$, respectively $(P=0.99)$.

Twelve patients (40\%) in the epinephrine group and 14 patients (43.8\%) in the budesonide group required re-nebulization $(P=0.76)$. The median time taken from initiation of study treatment to need for subsequent re-nebulization was significantly longer in epinephrine group as compared to budesonide group [(120 (60-720) min vs 90 (60-240 min)], $(P=0.04)$. Re-nebulized patients who developed hypoxia or showed signs of increased work of breathing were re-intubated. The proportion of patients needing re-intubation was similar in both the groups [epinephrine: 8 (25\%) and budesonide: 6 (20\%); $P=0.64]$. The median time to re-intubation was also similar [budesonide: 120 (120-720) min and epinephrine: 150 (60-720) $\mathrm{min}]$.

The trends in RR, HR, systolic and diastolic BP and $\mathrm{SpO}_{2}$ in both groups were not significantly different when assessed over time. Frequency of sinus tachycardia within 2 hours of aerosolized therapy was similar in both the groups [10 (31.3\%) in epinephrine vs 7 (23.3\%) in budesonide group]. Transient hypertension was noted in 4 patients (12.5\%) in epinephrine as compared to 2 (6.7\%) in budesonide group.

\section{Discussion}

The incidence of post-extubation stridor in our patients was $31.6 \%$, similar to that reported previously $(12,13)$. Both aerosolized epinephrine and budesonide were similar with respect to their rapid therapeutic action. Epinephrine, however, showed a statistically significant sustained effect at 2 hours post-nebulization. The proportion of patients with stridor score $\geq 4$, need for re-intubation and renebulization were similar in both the groups. The frequency of adverse effects in both the groups were also similar.

The rapid onset of action of aerosolized epinephrine and budesonide postulated due to local vasoconstrictor effect mediated by $\alpha$-adrenergic receptors has been observed by several authors(6,7, $9,11,15)$. Our findings in the epinephrine group are in concordance with observations of Westley, et al.(7) and Waisman, et al.(15) who had shown a similar change in croup score at 30 min post nebulization lasting for 60-90 min. Rapid response with budesonide observed by us was also similar to the findings of Husby, et al.(9) and Fitzgerald, et al.(11), who reported a significant change in the 


\section{What is AlREady KnOWn?}

- Both epinephrine and budesonide are similar in efficacy and safety in infective croup.

\section{What This Study Adds?}

- Both aerosolized epinephrine and budesonide are equally effective in their rapid therapeutic response in post-extubation stridor.

mean croup scores from baseline to 30 min postnebulization $(9,11)$. The trend of response observed by us at 2 hours post nebulization was different in that epinephrine showed a significant and sustained improvement as compared to budesonide. Majority of the published reviews have, however, reported a trend to the contrary - supporting the contention that the response to nebulized epinephrine is rapid and transitory and that to budesonide more sustained(7, 10,16). Klassen, et al.(16) and Godden, et al.(10) found a significant reduction in croup scores at 4 hours and 2 hours with aerosolized budesonide in the treatment of children with croup, thus reiterating the sustained nature of the drug effect. The sustained effect of steroids is attributed to their antiinflammatory effects, which are usually not apparent until 6 hours after treatment(9). The statistically significant difference in the therapeutic response between epinephrine and budesonide observed by us at 2 hours was possibly not clinically meaningful as the proportion of patients with a stridor score of $\geq 4$ in both groups was similar at that point. Additionally, the subsequent rate of re-nebulization and reintubation was also similar in both the groups. Since there were more patients with raised intracranial pressure in the latter, it is possible that the poor outcomes in the form of worsening stridor scores were related to the effects of raised ICP causing aggravation of airway problems and not to the direct drug effect per se.

The incidence of re-nebulization, though similar in both the groups, was higher than that reported previously(11). The lower incidence observed by Fitzgerald, et al.(11) was possibly related to the additional effect of systemic steroids that were given in 14 (40\%) and 15 (48.4\%) patients in the budesonide and epinephrine group, respectively. The reasons for the relatively higher incidence in our patients remains unclear. Nearly one-third of patients in both groups had sinus tachycardia within 2 hours of aerosolized therapy unlike the previously reported trend $(6,15,17)$. Tachycardia in the budesonide group was probably secondary to worsening stridor scores and increased work of breathing rather than to direct drug effect as seen in the epinephrine group. Transient systolic hyper-tension was noted in minority of patients in both the groups. Though the dose used in our study was similar to others, most of the studies have reported lack of significant change in blood pressure with both the drugs $(6,7,9,10)$.

The major limitation of our study is inclusion of patients with upper airway disease. Though evenly distributed, these are different pathologies bearing different post extubation criteria and course. Additionally, the poor therapeutic response noted with either drug needs to be studied in the context of the basic underlying etiology, that can have an important bearing on airway problems.

Contributors: AS: Data collection, statistical analysis and drafting of manuscript. JM: Concept, study design and planning, analysis and drafting of manuscript. SS: Study design and planning, and critical review of manuscript.

Funding: None.

Competing interests: None stated.

\section{REFERENCES}

1. McGovern FH, Fitz-Hugh GS, Edgemon LJ. The hazards of endotracheal intubation. Ann Otol 1971; 80: 556-564.

2. Anene O, Meert KL, Uy H, Simpson P, Sarnaik AP. Dexamethasone for the prevention of post extubation airway obstruction: A prospective, randomized, double-blind, placebo-controlled trial. Crit Care Med 1996; 24: 1666-1669.

3. Jordan WS, Graves CL, Elwyn RA. New therapy 
for post intubation laryngeal edema and tracheitis in children. JAMA 1970; 212: 585-588.

4. Goddard JE, Phillips OC, Marcy JH. Betamethasone for prophylaxis of postintubation inflammation: A double blind study. Anesth Analg 1967; 46: 348-353.

5. Pender JW. Endotracheal anesthesia in children: advantages and disadvantages. Anesthesiology 1954; 15: 495-506.

6. Nutman J, Brooks LJ, Deakins K, Baldesare K, Witte M, Reed M. Racemic versus L-epinephrine aerosol in the treatment of postextubation laryngeal edema: Results from a prospective, randomized, double-blind study. Crit Care Med 1994; 22: 1591-1594.

7. Waisman Y, Klein BL, Boenning DA, Young GM, Chamberlain JM, O'Donnell R, et al. Prospective randomized double-blind study comparing Lepinephrine and racemic epinephrine aerosols in the treatment of laryngotracheitis (croup). Pediatrics 1992; 89: 302-306.

8. Meade MO, Guyatt GH, Cook DJ, Sinuff T, Butler R. Trials of corticosteroids to prevent postextubation airway complications. Chest 2001; 120: 464S-468S.

9. Husby S, Agertoft L, Mortenson S, Pedersen S. Treatment of croup with nebulised steroid (budesonide): a double bind, placebo controlled study. Arch Dis Child 1993; 63: 352-355.
10. Godden CW, Campbell MZ, Hussey M, Cogswell JJ. Double blind placebo controlled trial of nebulised budesonide for croup. Arch Dis Child 1997; 76: 155-158.

11. Fitzgerald D, Mellis C, Johnson M, Allen H, Cooper P, Van Asperen P. Nebulized budesonide is as effective as nebulized adrenaline in moderately severe croup. Pediatrics 1996; 97: 722-725.

12. Tellez DW, Galvis AG, Storgion SA, Amer HN, Hoseyni M, Deakers TW. Dexamethasone in the prevention of postextubation stridor in children. $\mathrm{J}$ Pediatr 1991; 118: 289-293.

13. Kemper JK, Benson MS, Bishop MJ. Predictors of postextubation stridor in pediatric trauma patients. Crit Care Med 1991; 19: 352-355.

14. Koka BV, Andre JM, Smith RM, Jeon IS, Mackay I. Postintubation croup in children. Anesth Analg 1977; 56: 502-505.

15. Westley CR, Cotton EK, Brooks JG. Nebulized racemic epinephrine by IPPB for the treatment of croup. Am J Dis Child 1978; 132: 484-487.

16. Klassen P, Feldman E, Watters K, Sutcliffe T, Rowe C. Nebulized budesonide for children with mild-to-moderate croup. N Engl J Med 1994; 331: 285-289.

17. Fogel JM, Berg IJ, Gerber MA, Sherter CB. Racemic epinephrine in the treatment of croup: nebulization alone versus nebulization with intermittent positive pressure breathing. J Pediatr 1982; 25: 1028-1031. 